\title{
Pensando e criando: o talento em foco
}

\author{
Reasoning and creating: talent as a focus.
}

Virgolim, A. M. R. (Org.). (2007). Talento criativo: expressão em múltiplos contextos.

Brasília: Editora Universidade de Brasília.

Talento criativo em múltiplos contextos revela pelas mãos da organizadora $\mathrm{o}$ crescente $\mathrm{e}$ apaixonado interesse de um grupo de pesquisadores brasileiros pelo tema criatividade e superdotação. Mais que uma coletânea de textos, o livro se apresenta como marco de uma série histórica da produção acadêmica conjunta do Grupo de Pesquisa em Processos Criativos e Superdotação, afiliado à Plataforma Lattes Institucional do Conselho Nacional de Desenvolvimento Científico e Tecnológico $(\mathrm{CNPq})$ coordenado pelas professoras Eunice Lima Soriano de Alencar e Denise de Souza Fleith. Desde a década de 1980, o grupo vem se consolidando a partir do trabalho pioneiro iniciado na Universidade de Brasília e responde hoje por boa parte da produção científica sobre criatividade e superdotação no Brasil. Atualmente o grupo conta com a participação de vários pesquisadores de qualificadas universidades do país. Tem como prioridade o desenvolvimento de pesquisas e a disseminação do conhecimento dessas áreas em suas múltiplas dimensões e determinantes, considerando como relevante o contexto históricosocial, com destaque para o papel da família, da escola e da sociedade como agentes de reconhecimento, desenvolvimento e expressão do potencial criativo, do talento e da inteligência.

A obra destaca uma amostra das linhas de interesse, resultados de pesquisas e de revisão de literatura conduzidos pelos membros do grupo até o ano de 2001. Uma preocupação eminente nesta primeira sistematização foi garantir a essência individual da produção de cada autor, sua linguagem e referenciais teóricos sem abandonar o caráter mais consistente da obra que é o entusiasmo, que cada um traz, na expressão criativa particular em torno desta temática.

A relevância da matéria nos dias atuais traduz o desejo de uma época, embora ainda pouco inculcado ou revelado por grande parte da população em diversas localidades do mundo, o desejo de aprender inerente ao ser humano, quando institucionalizado ou formalizado, ganha outras dimensões, passa a se definir a partir do tempo, do espaço, do currículo, da avaliação e da dimensão criativa muitas vezes abandonada. Apesar da evidente lacuna no enfoque educacional quanto ao talento e à criatividade, deve-se persistir na idéia de que estes processos, desde muito cedo na história do indivíduo, devem ser incentivados e oferecidos dentro de um ensino efetivo e eficaz segundo as características e condições de cada um, especialmente àquelas relacionadas ao desenvolvimento e ciclo de vida sócio-cultural e afetivo. Ainda hoje esse pensamento não encontrou ressonância nas políticas públicas e no modo de pensar de muitos grupos sociais, em plena sociedade do conhecimento e era da informação. 
Os desdobramentos empíricos em torno do talento criativo têm sinalizado de modo contundente que a sociedade deve pautar-se pela identificação, valorização e desenvolvimento de indivíduos e de sistemas criativos, para dar conta das demandas atuais e futuras de resoluções de problemas, que irão permitir grandes avanços e uma melhor qualidade de vida à humanidade. Essa temática é de marcado interesse no cenário internacional em que a preocupação com o potencial humano e suas formas de expressão tem sido reconhecida como fator de prosperidade para o indivíduo e para a sociedade. Deste modo, a criatividade vem despertando o interesse de estudiosos de diversas áreas. No contexto educacional mundial se observa o despontar desse interesse por parte de alguns países, justamente por ser a escola identificada como o lugar da infância e da juventude na sociedade contemporânea. No entanto, a escola como instituição específica de transmissão de cultura e espaço educativo qualificado tem falhado em sua missão como agente promotor de criatividade e de reconhecimento do talento e da inteligência, ora por não ter ocupado verdadeiramente seu espaço na construção de um currículo criativo, com estratégias de ensino que favoreçam a imaginação e o pensamento flexível e divergente, ora por não conhecer e dominar o assunto, alimentando mitos e idéias estereotipadas sobre esse tópico.

O tema central do livro é desenhado por Ângela Magda Virgolim, autora organizadora, a partir de uma sinopse, em que a mesma problematiza suas teses sobre criatividade e superdotação e apresenta os demais colaboradores e suas respectivas abordagens. Ensaia ainda, uma apreciação aos trabalhos de seus pares e esclarece que sua preocupação principal foi sistematizar em um único material um recorte das produções e discussões advindas dos trabalhos do Grupo de Pesquisa. Neste contexto, Virgolim prepara o leitor para os temas que serão desenvolvidos nos oito capítulos organizados no decorrer do livro, sugerindo uma apreensão cuidadosa do texto apresentado no prefácio, que teve por objetivo situar o campo de estudo numa trajetória interessante do ponto de vista histórico, ao propor uma revisão cronológica das principais contribuições aos estudos da criatividade, destacando o problema da definição do construto, ao mesmo tempo em que apresenta os mais ilustres pensadores, suas idéias e definições sobre o tema.

No primeiro capítulo sob o título Criatividade e saúde mental; desafio à família e à escola, Virgolim enfatiza a importância do estado da arte em criatividade e destaca que o momento atual é promissor para o avanço do tema em variados contextos, organizacional, educacional, familiar e pessoal. Ancora suas idéias na perspectiva humanista para a qual criatividade é entendida como um importante fator para a promoção da saúde mental, uma vez que o impulso criativo possibilita ao indivíduo lidar eficientemente com as tensões e conflitos do cotidiano. Nesta direção, defende que o incentivo ao desenvolvimento da expressão criativa deve ocorrer o quanto antes na vida dos indivíduos de modo planejado e sistemático promovido tanto pela escola quanto pela família, numa atmosfera enriquecedora e estimulante. Chama atenção também, para a dificuldade que o contexto educacional apresenta em se organizar de maneira mais flexível e criativa 
no atendimento aos alunos, de modo a romper com uma estrutura tradicional na maneira de ensinar e aprender. Para esclarecer esse pensamento descreve os resultados obtidos em pesquisa de sua autoria sobre habilidades de pensamento criativo em alunos de escolas do tipo aberta, intermediária e tradicional, em que se observaram diferenças significativas para esse fator em favor de alunos de escolas do tipo aberta e intermediária.

No Capítulo 2, Criatividade e saúde nos indivíduos e nas organizações, Albertina Mitjáns Martínez lança um olhar sobre criatividade fundamentado na perspectiva histórico-cultural, para a qual o ato de criar está imbricado em configurações subjetivas tanto do indivíduo que cria, quanto na subjetividade de seu contexto social. A autora situa a criatividade como um processo do sujeito psicológico, plurideterminada e mediatizada por fatores históricos e socioculturais, portanto está relacionada com a condição subjetiva e sóciohistórica do homem e neste sentido, se vincula à idéia de saúde. Para a autora, saúde é entendida como um processo de funcionamento integral que aumenta e otimiza os recursos do organismo, potencializando-os diante de processos de adoecimento e doenças. Criatividade e saúde possuem dimensões subjetivas essenciais e complexas que podem ser analisadas do ponto de vista da emoção expressa no viver cotidiano e pelas configurações subjetivas presentes no processo de desenvolvimento e de educação da criatividade como lócus de promoção da saúde. Para tanto, se faz necessário transcender ao modelo biomédico e à visão fragmentada do homem, afinal o mundo é construído pela razão e criatividade do homem, ou seja, é modificado pelo próprio homem.
No Capítulo 3, Mônica Neves-Pereira também destaca a complexidade do fenômeno da criatividade ressalvando a construção do sujeito histórico a partir da interação com o meio sociocultural e a criação como resultado dessa interação. A autora se propõe a uma investigação conforme o próprio título do capítulo anuncia Uma leitura histórico-cultural dos processos criativos: as contribuições de Vygotsky e da psicologia soviética. O texto apresentado neste capítulo traduz de maneira muito clara os conceitos fundamentais da obra de Vygotsky e conduz o leitor ao entendimento do tema criatividade a partir desse aporte teórico. Cada conceito é alinhavado na direção de uma perspectiva dialética aberta a novas possibilidades no escopo da criatividade, para além da visão centrada no sujeito criativo, em seus processos e em seus produtos. A autora defende a condição indissolúvel do pensar e criar e alerta que as iniciativas que tenham estes objetivos deverão contemplar tanto cognição quanto afetividade na promoção do desenvolvimento do pensamento criativo.

No Capítulo 4 intitulado $A$ institucionalização de crianças e a criatividade, Paulo Gomes de Souza-Filho traz uma preocupação inusitada ao campo de pesquisa da área baseado em dados obtidos em investigações de sua autoria. Muito comum na literatura do pós-guerra, essa temática, institucionalização de crianças e jovens, teve certo declínio nos estudos de várias áreas principalmente nas comunidades européias. No entanto, o autor chama atenção para o fato de o Brasil ainda abrigar inúmeras crianças em instituições substitutivas do lar, algo que ele considera bastante grave e comum, apesar dos avanços adquiridos com o advento do 
Estatuto da Criança e do Adolescente (ECA). A consciência do enorme prejuízo causado à sociedade por abandonar suas crianças e jovens à má sorte e da dívida social para com esses sujeitos que afeta a todos, ricos e pobres, mobiliza recursos de todas as ordens especialmente no setor público e incorpora, ao menos no discurso, cuidados especiais com esses grupos etários. As medidas de proteção e as medidas sócio-educativas ainda são tímidas e estão assentadas num modelo excludente que não leva em consideração o sujeito no processo. Os recursos investidos são da ordem da assistência social e não primam para a maximização de desenvolvimento e expressão da criatividade, por imperar características impessoais. O autor destaca os efeitos deletérios que o sistema de institucionalização acarreta ao desenvolvimento da personalidade do indivíduo e principalmente no desenvolvimento de seu potencial criativo.

O Capítulo 5, escrito a duas mãos, traz a experiência da professora Eunice Soriano de Alencar aliada à inovação do pensamento de Afonso Galvão para discutir sobre as Condições favoráveis à criação nas ciências e nas artes evidenciando os fatores fundamentais para o alcance de uma expressão criativa mais significativa, em face das múltiplas áreas de manifestação e no grau variado que se apresentam nas diversas dimensões do fazer humano. Com esse objetivo, discutem os aspectos da criação intelectual sob o prisma das ciências e das artes considerando que em ambos estão presentes essencialmente os mesmos métodos de pensamento. Enfatizam o papel das forças sociais existentes desde o início da vida dos indivíduos que ampliam ou limitam sua capacidade de expressão e que determinam o grau de autoconfiança que a pessoa empreenderá em suas produções ao longo do curso de vida. Realçam também estratégias que devem ser inseridas nos repertórios dos indivíduos para encorajar o desenvolvimento do talento criativo e depositam na escola a grande responsabilidade para a concretização desta tarefa.

$\mathrm{Na}$ seqüência Afonso Galvão fomenta discussões a respeito do talento artístico e da influência do ambiente na organização da expertise principalmente a musical. Descerra o Capítulo 6, intitulado A questão do talento: usos e abusos, desmistificando a noção de talento, problematizando as dificuldades em torno de uma definição mais consensual e aprofundada e destacando os mitos que ainda persistem no entendimento do conceito. Enfatiza as variações culturais em torno do talento criativo que, aliado às influências históricas, originam e influenciam também a qualidade da performance relacionada a um determinado talento. A partir da revisão de várias pesquisas que investigaram o talento musical argumenta que talento é a gradação de facilidade que alguém pode ter em uma determinada atividade a partir de um referencial preestabelecido, portanto envolve um referencial que é socialmente construído e que não admite "fórmulas mágicas". O autor ensaia também uma discussão em torno da dicotomia entre os conceitos de expertise e de talento. Com base em evidências empíricas, o autor salienta que o primeiro está associado à condição de um estudo deliberado que o distingue diferentemente do talento que, embora exija dedicação e empenho, possui um caráter mais flexível. 


\section{A promoção da criatividade no contexto escolar} é abordada no sétimo capítulo por Denise de Souza Fleith. A autora demonstra com sugestões práticas um viés de técnicas e exercícios estimuladores do potencial criativo, passíveis de serem aplicados em programas de desenvolvimento da criatividade e especialmente no contexto de sala de aula. Seus exemplos são dirigidos a professores e podem ser aplicados de maneira interdisciplinar. Outra preocupação da autora refere-se não só à aprendizagem de comportamentos criativos, mas, sobretudo, ao desenvolvimento integral de habilidades criativas que contribuam também com o desenvolvimento afetivo dos alunos e a formação de um autoconceito positivo. As barreiras que obstruem a consolidação dos processos criativos são revisitadas e criticadas pela autora, ao mesmo tempo em que propõe mecanismos para a superação de modelos educacionais tradicionais, que levam apenas à reprodução do conhecimento. Alguns modelos internacionais de promoção da criatividade são considerados como alternativas de promoção à um clima de sala de aula mais criativo, bem como as contribuições advindas dos trabalhos das brasileiras Eunice Alencar e Maria Helena Novaes, nesta mesma direção. Para a autora urge que se busquem alternativas no contexto educacional para garantir o direito dos estudantes a um ensino de qualidade que prime pelo desenvolvimento de potencialidades em múltiplos aspectos e contextos, por meio de um currículo avançado e estimulador e estratégias pedagógicas inovadoras.

No oitavo e último capítulo, Uma proposta para o desenvolvimento da criatividade na escola é apresentada pela autora organizadora à luz do modelo desenvolvido por Joseph Renzulli, pesquisador do Centro Nacional de Pesquisa para o Superdotado e Talentoso (NRCG/T) da Universidade de Connecticut. O Modelo de Enriquecimento Escolar (SEM) é detalhado em todas as suas nuances e perspectivas. A autora enfatiza a complexidade que envolve o modelo, desde sua argumentação teórica à concretização aplicada. O modelo possui três divisões para garantir o aporte teórico-filosófico, a identificação do grupo de estudantes com características de comportamento criativo/produtivo e aplicabilidade prática de encorajamento à ação produtiva criativa. Portanto, o SEM é considerado completo por abarcar três dimensões que sustentam seu entendimento e aplicabilidade, ou seja, a definição, a identificação e o enriquecimento, respectivamente formalizados no Modelo dos Três Anéis, Modelo de Identificação das Portas Giratórias e Modelo Triádico de Enriquecimento. O SEM encontrou grande acolhida no Brasil por seu caráter democrático, inclusivo e de aplicabilidade prática dentro do sistema escolar.

Em análise, as contribuições desta literatura são primordiais à compreensão de muitos fenômenos que se verificam no contexto educacional, em especial o desperdício de talentos, a falta de equidade no desenvolvimento de potencialidades, a incompatibilidade de desempenhos e a exclusão de minorias. Os autores são unânimes em afirmar a força e a influência do contexto histórico-social no desenvolvimento da pessoa e de suas múltiplas particularidades comportamentais, personológicas e de desenvolvimento. Ao reconhecer a importância do contexto e da interação dos vários sistemas que o integram, os autores constroem caminhos na promoção de um desenvolvimento mais harmonioso 
para o indivíduo. $\mathrm{O}$ enlace entre escola e família é essencial na medida em que é nesse território que se manifestam as diferenças culturais e sociais dadas pela história, em que se formaliza a dialética entre a socialização e individualização da pessoa e de seu potencial criativo como um processo individual e um produto social. Se hoje a família busca a segurança para o ensino formal de seus filhos na escola, também a escola busca na família a aprendizagem e a formação de seus alunos. Isso porque, com as transformações instantâneas nos diversos aspectos da vida, a parceria entre essas duas instituições se tornou imprescindível para a construção da autonomia e da formação de indivíduos capazes de assumir uma postura crítica e criativa frente às demandas do mundo moderno. É neste sentido que os autores, cada um a seu modo, ressaltam a importância de estimular e despertar a criatividade do indivíduo já nos primeiros anos de sua existência e de promover uma continuidade no encorajamento da expressão do talento criativo ao longo do curso de vida.

\section{Vanessa Terezinha Alves Tentes de Ourofino} (vanessatentes@unb.br ou psivan@terra.com.br)-psicóloga clínica e escolar, mestre em Psicologia pela Universidade de Brasília (UnB). Atualmente é doutoranda no programa de pós-graduação em Processos de Desenvolvimento Humano e Saúde do Instituto de Psicologia da UnB 